\title{
Variability in Nutritional Composition, Kernel Morphology and Cooking Quality of Selected Rice in Xingan Meng from Northeast China
}

\author{
Hong Zhu ${ }^{1, *}$, Ke-hong Liang ${ }^{1}$, Ju Qiu ${ }^{1}$, Jing Wang ${ }^{1}$, and Zhi-yuan $\mathrm{Ji}^{2}$,* \\ ${ }^{1}$ Institute of Food and Nutrition Development, Ministry of Agriculture and Rural Affairs, 100081 Beijing China \\ ${ }^{2}$ Institute of Crop Sciences, Chinese Academy of Agricultural Sciences, 100081 Beijing China
}

\begin{abstract}
Paddy rice cultivation expanded in Northeast China, and Xingan Meng of Inner Mongolia is an emerging area of rice production area. The goals of this study: i) to investigate varietal differences in levels of nutritional quality, kernel morphology and cooking quality and ii) to identify clusters of rice samples from Xingan Meng, northeast part of China. Research was conducted in Xingan Meng, China during the 2019 rice-growing season. The nutritional quality (energy, protein, carbohydrate, lipid, amylose, ash, Ca, $\mathrm{Na}, \mathrm{Fe}, \mathrm{Zn}, \mathrm{Mn}$ ), cooking quality (alkali spreading value, gel consistency) and kernel morphology (length, width, length width ratio, chalky rice percentage, chalky rice degree) were analysed. Significant difference were found across all traits. The largest variation was found for $\mathrm{Mn}$, followed by $\mathrm{Ca}, \mathrm{Fe}$ and $\mathrm{Zn}$ content. Four principal components were found that accounted for $95.14 \%$ of overall variability. Cluster analysis sorted the rice sample into four clusters based on nutritional quality, kernel morphology, and cooking quality. The findings of this study can support to demonstrate the quality of rice from Xingan Meng, northeast part of China.
\end{abstract}

\section{Introduction}

Rice is one of the most important staple foods for people around the world. Different types of rice provide many essential elements, nutrients, fibers and vitamins that are beneficial to humans ${ }^{[1]}$. Due to the high preference of the world population for this food, rice is constantly being the subject of several studies. Authentication of rice is one of the most addressed concerns in the current literature, and is usually concerned with the recognition of its geographical origin.

A number of driving factors, including global warming, advancements in agricultural technology, market demand, and agricultural policies have led to the expansion of paddy rice in northeast China over the most recent decades ${ }^{[2 ; 3]}$. Thus, the rapid expansion of paddy rice area in northeast China has made the region an emerging paddy rice production base ${ }^{[4]}$. In northeast China, paddy rice cultivation expanded primarily in Heilongjiang, Jilin, and Liaoning provinces. While a wide diversity of rice varieties provides different qualities (appearance, flavour, texture, and taste) suitable for various cuisines around the world, certain rice varieties with unique and preferred qualities are considered as premium rice with higher market value due to higher demands from consumers. Many Chinese people believe that rice grains in Northeast China taste much better rice grains in southern of China and have less concern for soil and water pollution, which has also contributed to higher profits for rice farms and the expansion of paddy rice areas in northeast China.

Genetic background and cultivation location (soil and climate factors) play important roles on unique characteristics of the rice. Over the past few years, geographical indication of rice product is identified by kernel morphology (length, width, colour, and shape), physio-chemical properties (amylose content, starch, and protein characteristics) ${ }^{[5 ; 6]}$, cooking and eating qualities, and aroma characteristics ${ }^{[7]}$, and the details of location and variety are properly labelled. Therefore, characterization of rice nutritional composition, cooking quality and kernel morphology is an important issue for cultivators, nutritional researchers, and rice breeders. Overall discrimination of rice has been widely performed in the recent literature with the aid of multivariate data analysis and data mining techniques. Both processes offer powerful methods capable of performing statistical and predictive analysis over data sets described by many variables. In the case of rice, such variables can be chemical elements, physicochemical properties, climate parameters and many others.

This article focused on selected rice from Xingan Meng of Inner Mongolia, as an emerging area of rice production area in northeast of China, which is not reported in literature. Using multivariate data analysis, the variation of nutritional composition, kernel morphology and cooking quality of rice produced in Xinan Meng were characterized.

Corresponding author: zhuhong@caas.cn 


\section{Materials and Method}

\subsection{Experimental design}

18 rice samples were collected from Xingan Meng of northeast part of China, which are respectively the most popular six varieties: DHX2, JD, YZ, NLYZ, BDB, and LY. These genotypes were planted in the 2019 rice growing season (June-December 2019) at the experiment field of the Xingan Meng, $\left(122^{\circ} 03^{\prime} 818^{\prime \prime} \mathrm{N}\right.$, $46^{\circ} 08^{\prime} 208^{\prime \prime}$ E, and $275 \mathrm{~m}$ above sea level) using a randomized complete block design (RCBD) with three replications. Each genotype was planted as an experimental unit of four $1 \times 5 \mathrm{~m}$ plots, with $45 \mathrm{~cm}$ between plots. The seedlings were transplanted at a hill spacing of $15 \times 15 \mathrm{~cm}$, with a single seedling per hill. Soil preparation, planting, and other agronomic practices were carried out uniformly following the recommendations for good agricultural practices (GAP). Ten panicles per genotype were randomly harvested depending on their harvesting maturity stages (data not shown) and oven-dried at $50{ }^{\circ} \mathrm{C}$ to a moisture content $<14 \%$. Seeds were manually dehulled. Samples were milled to a fine powder, passed through a 100-mesh screen mesh, thoroughly mixed, and stored at $-20{ }^{\circ} \mathrm{C}$ until analysis.

\subsection{Analysis of nutritional composition}

Levels of crude protein, crude fat, ash, minerals, and were determined according to the Association Official Analytical Chemists (AOAC) method. Crude protein content was estimated by determining the total nitrogen using the Kjeldahl method (AOAC, 2005a) ${ }^{[8]}$. Crude fat was analysed by the Soxhlet extraction method (AOAC, $2005 b)^{[9]}$. Ash content was estimated by gravimetric measurement of the sample residue after ignition in an oven at $600^{\circ} \mathrm{C}$ to a constant weight (AOAC, 2005c $)^{[10]}$. Levels of calcium, sodium, iron, zinc, magnesium, and manganese were determined by inductively coupled plasma optical emission spectrometry (Integra XL Inductively Coupled Plasma Optical Emission Spectrometer; GBC, Melbourne, Australia) according to the AOAC method 999.11 (AOAC, 2000 ${ }^{[11]}$. The amylose content was determined by the method UNI ISO 6647 (UNI ISO, 2008).

\subsection{Analysis of cooking quality}

Alkali test. The alkali spreading value was conducted as suggested by Mariotti ${ }^{[2]}$. The gel consistency was determined according to Chinese national standard (GB/T 17891-1999).

\subsection{Analysis of kernel morphology}

Length, width, chalky rice percentage, and chalkiness degree was assessed according to the method of NY/T 593-2013 and GB/T 17891-1999 ${ }^{[13]}$.

\subsection{Statistical Analysis}

The results were analyzed from the mean of determinations for duplicate samples prepared for each samples. Analysis of variance (ANOVA) was performed in SPSS 19 (SPSS Inc. Chicago, IL, USA). Coefficients of variation (CV) were calculated from the ratios between standard deviations (SD) and population means, to represent the variability among samples. Hierarchical agglomerative clustering was then conducted for nutritional, cooking, and appearance quality using the Ward criterion, performed using $\mathrm{R}$ ( $\mathrm{R}$ studio. Boston, MA, USA). A heat map showing Pearson's correlation coefficients for nutritional parameters and cooking qualities was constructed using $\mathrm{R}$ as well.

\section{Results and discussion}

\subsection{Analysis of Variance}

Descriptive statistics for the nutritional quality (energy, carbohydrate, protein, fat, amylose, ash, $\mathrm{Ca}, \mathrm{Na}, \mathrm{Fe}, \mathrm{Zn}$, and $\mathrm{Mn}$ contents), cooking quality (alkali spreading value and gel consistency) and kernel morphology (length, width, chalky rice percentage, and chalkiness degree) of the rice are shown in Table 1. Among nutritional quality, large variation was observed in $\mathrm{Mn}$ content with a CV of $30.54 \%$, followed by $\mathrm{Ca}, \mathrm{Fe}$ and $\mathrm{Zn}$. The lowest variation was found for $\mathrm{Na}$ content $(\mathrm{CV}=0.89 \%)$ and carbohydrate $(1.14 \%)$.

Two groups could be distinguished by distribution of protein (Fig. 1A). The first had protein content of between $5.0 \%$ and $6.0 \%$ of dry weight, and the second had protein of between $6.6 \%$ and $7.0 \%$. The content of carbohydrate falls into two classes, and most samples had higher content (from 77.5 to $80.0 \mathrm{~g} / 100 \mathrm{~g}$ ) (Fig. 1B). The frequency distribution for lipid and ash content was continuous, ranging from 0.6 to $0.9 \mathrm{~g} / 100 \mathrm{~g}$, and from 0.26 to $0.38 \mathrm{~g} / 100 \mathrm{~g}$, respectively (Fig. 1C, D). Three separate groups were found in content of amylose (Fig. 1E). As for cooking qualities, the frequency distribution for alkali spreading value was continuous, ranging from 6.0 to 7.2 (Fig. 1F). Two groups could be distinguished by distribution of gel consistency (Fig. 1H). Most samples had higher value (from 70 to 100). Wide variation was also observed in chalky rice percentage, which ranged from $1.70 \%$ to $10.83 \%$ (Fig. 1I). Chalkiness degree also showed big variation, with a range from $0.39 \%$ to $2.12 \%$ (Fig. 1G).

The range in the nutritional composition levels of grains may be due to a combination of genetic variability, soil conditions, and environmental factors ${ }^{[14]}$. Further study will be required to elucidate the relationship between factors such as climate or soil quality and agricultural practices. 
Table 1. Descriptive statistics for nutritional composition, kernel morphology and cooking quality of the 18

\begin{tabular}{llccll}
\hline Parameter & Mean \pm SD & Min. & Max. & CV & F-value \\
\hline Energy $(\mathrm{kJ} / 100 \mathrm{~g})$ & $1460.67 \pm 9.88$ & 1440 & 1479 & 0.68 & 20.852 \\
Carbohydrate $(\mathrm{g} / 100 \mathrm{~g})$ & $78.21 \pm 0.89$ & 76.1 & 79.5 & 1.14 & 10.832 \\
Protein $(\mathrm{g} / 100 \mathrm{~g})$ & $6.13 \pm 0.69$ & 5.19 & 6.87 & 11.32 & 352.869 \\
Lipid $(\mathrm{g} / 100 \mathrm{~g})$ & $0.73 \pm 0.08$ & 0.60 & 0.86 & 11.23 & 43.059 \\
Amylose $(\%)$ & $14.19 \pm 0.95$ & 12.93 & 15.46 & 6.68 & 1482.934 \\
Ash $(\mathrm{g} / 100 \mathrm{~g})$ & $0.32 \pm 0.03$ & 0.31 & 0.36 & 8.73 & 115.554 \\
$\mathrm{Ca}(\mathrm{mg} / 100 \mathrm{~g})$ & $5.71 \pm 0.82$ & 4.42 & 6.71 & 14.40 & 162.633 \\
$\mathrm{Na}(\mathrm{mg} / 100 \mathrm{~g})$ & $0.90 \pm 0.01$ & $\mathrm{~N} . \mathrm{d}$. & 0.90 & 0.89 & 37968.750 \\
$\mathrm{Fe}(\mathrm{mg} / 100 \mathrm{~g})$ & $0.26 \pm 0.04$ & 0.25 & 0.30 & 14.97 & 83.833 \\
Zn $(\mathrm{mg} / 100 \mathrm{~g})$ & $1.12 \pm 0.16$ & 0.82 & 1.32 & 14.63 & 362.719 \\
Mn $(\mathrm{mg} / 100 \mathrm{~g})$ & $0.83 \pm 0.25$ & 0.60 & 1.32 & 30.54 & 2030.579 \\
Alkali spreading value & $6.71 \pm 0.29$ & 6.00 & 7.00 & 4.35 & 6.787 \\
Gel consistency (mm) & $75.17 \pm 14.36$ & 45 & 92 & 19.10 & 297.986 \\
Length $(\mathrm{mm})$ & $6.03 \pm 0.40$ & 6.033 & 6.214 & 6.63 & 3342.776 \\
Width $(\mathrm{mm})$ & $2.32 \pm 0.08$ & 2.281 & 2.208 & 3.56 & 2650.553 \\
Length width ratio & $2.61 \pm 0.24$ & 2.650 & 2.825 & 9.33 & 7537.758 \\
Chalky rice percentage $(\%)$ & $5.27 \pm 3.57$ & 1.70 & 10.83 & 67.75 & 607.939 \\
Chalkiness degree $(\%)$ & $1.03 \pm 0.58$ & 0.39 & 2.12 & 56.92 & 390.736 \\
\hline
\end{tabular}

A
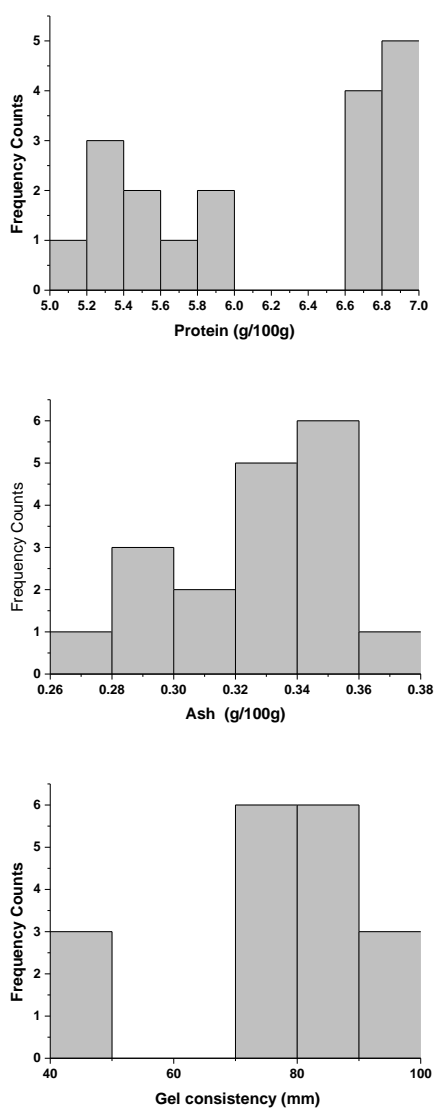
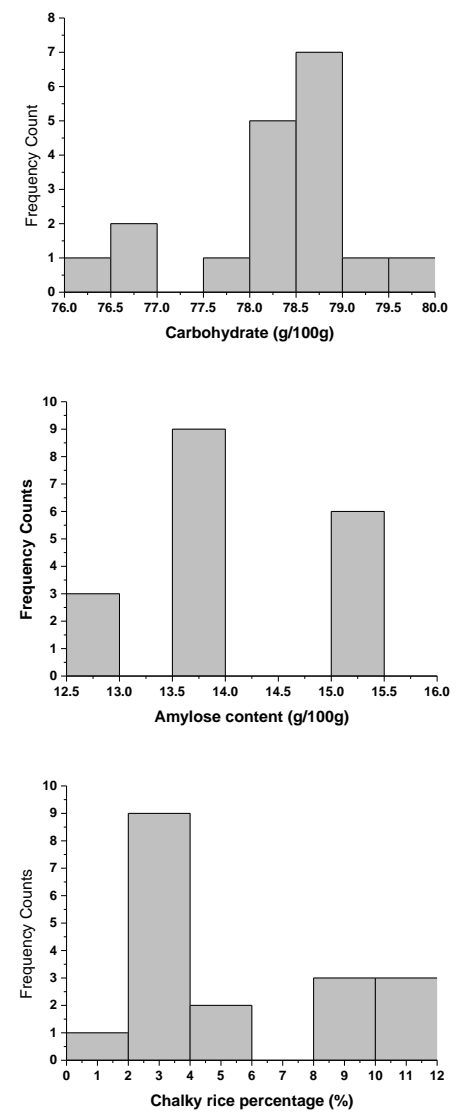

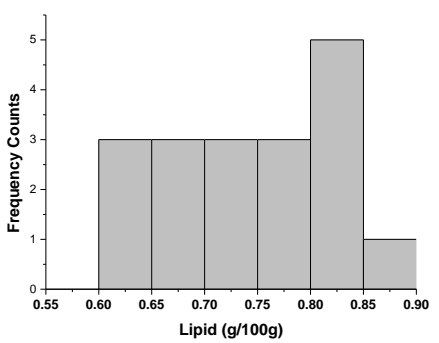

F
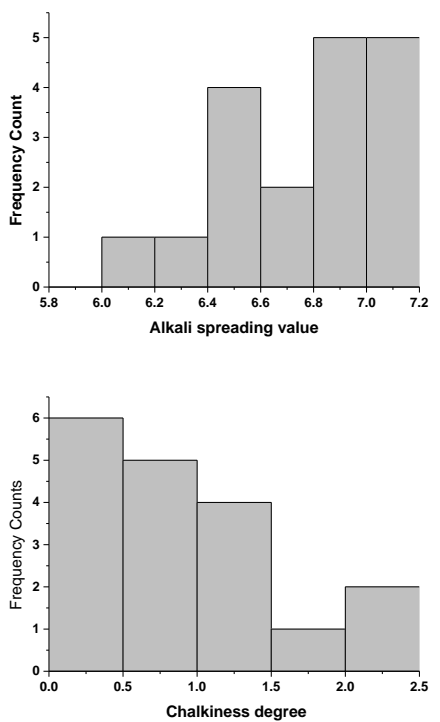

Fig. 1. Distribution of the 18 rice samples by protein (A), carbohydrate (B), lipid (C), ash (D), amylose (E), alkali spreading value (F), gel consistency $(\mathrm{H})$, chalky rice percentage $(\mathrm{I})$, and chalkiness degree $(\mathrm{G})$. 


\subsection{Multivariate Analysis}

One of the key challenges is the choice of variables to analyze, since more or less data are available on the geographical location, genotype, rice type, and other markers. The two most widely-used multivariate analysis techniques for interdependent responses of rice germplasm are principal component analysis (PCA) and hierarchical cluster analysis ${ }^{[15]}$. Principal components are extracted by order of contribution to the total variance and, by examining the loadings of the variables in the first components, it is possible to measure the relevance of each variable. The first four principle components are the most important in reflecting the variation among rice genotypes that is useful for genotypic classification ${ }^{[16]}$. In this study, the first four components contributed approximately $95.14 \%$ of the total variation (Table 2), giving a clear idea of the structure underlying the variables analyzed. The first principal component represented protein, $\mathrm{Ca}, \mathrm{Fe}, \mathrm{Zn}$, and length. The second component was mainly attributed to alkali spreading value, length width ratio, chalky rice percentage, and chalkiness degree. The third component was mainly contributed by energy, carbohydrate, gel consistency, and width. The fourth component was attributed mainly to lipid, ash, amylose, and Mn. These findings were in agreement with previous studies, which reported that ash and insoluble dietary fibre were the major factors contributing to variation of rice cultivars and other cereals $^{[17]}$.

Table 2. Coeffcients and vectors associated with the first four

\begin{tabular}{|c|c|c|c|c|}
\hline & First & Second & Third & Fourth \\
\hline Eigenvalues & 6.375 & 4.104 & 3.256 & 2.439 \\
\hline$\%$ Variance & 37.500 & 24.141 & 19.153 & 14.347 \\
\hline Cumulative $\%$ total & 37.500 & 61.641 & 80.794 & 95.140 \\
\hline \multicolumn{5}{|c|}{ Coefficient factor } \\
\hline Energy & 0.274 & 0.286 & 0.877 & -0.142 \\
\hline Carbohydrate & -0.451 & 0.368 & 0.725 & -0.074 \\
\hline Protein & 0.981 & -0.028 & -0.135 & -0.119 \\
\hline Lipid & -0.367 & -0.594 & -0.594 & -0.270 \\
\hline Amylose & 0.200 & 0.244 & 0.382 & 0.840 \\
\hline Ash & -0.316 & -0.860 & -0.151 & 0.283 \\
\hline $\mathrm{Ca}$ & 0.934 & -0.208 & 0.174 & -0.142 \\
\hline $\mathrm{Fe}$ & 0.833 & 0.042 & -0.208 & -0.492 \\
\hline $\mathrm{Zn}$ & 0.907 & -0.036 & 0.145 & 0.379 \\
\hline $\mathrm{Mn}$ & -0.192 & 0.204 & -0.155 & 0.946 \\
\hline $\begin{array}{l}\text { Alkali spreading } \\
\text { value }\end{array}$ & 0.110 & 0.844 & -0.322 & -0.122 \\
\hline Gel consistency & -0.381 & 0.011 & 0.847 & -0.302 \\
\hline Length & 0.523 & -0.779 & -0.028 & 0.280 \\
\hline Width & -0.505 & -0.742 & 0.354 & 0.070 \\
\hline Length width ratio & 0.460 & 0.725 & -0.450 & 0.164 \\
\hline $\begin{array}{l}\text { Chalky rice } \\
\text { percentage }\end{array}$ & -0.842 & 0.445 & -0.276 & 0.091 \\
\hline Chalkiness degree & -0.909 & 0.228 & -0.278 & -0.125 \\
\hline
\end{tabular}

The goal of clustering is to divide data into distinct clusters in such a way that samples associated with the same cluster are considered similar in the pattern found, whereas samples associated with different clusters are as dissimilar as possible ${ }^{[18]}$. Based on nutritional composition, kernel morphology, and cooking quality of 18 rice samples, four distinct clusters were identified (Fig. 2). Cluster I comprised the three samples (LY_1, LY_2, LY_3). Cluster II comprised six samples (YZ_1, YZ_2, YZ 3, NLYZ_1, NLYZ_2, NLYZ_3). This indicated that $\mathrm{YZ}$ is similar to NLYZ. Cluster III comprised three samples (BDB 1, BDB 2, BDB 3). Cluster VI comprised six samples (DHX2_1, DHX2_2, DHX2_3, JD1_1, JD1_2, JD1_3), which demonstrated that $\mathrm{DH}$ X2 was similar to JD1. The information obtained through cluster analysis was particularly useful as the best performing genotypes fell within one cluster, allowing them to be differentiated from the others ${ }^{[19]}$.

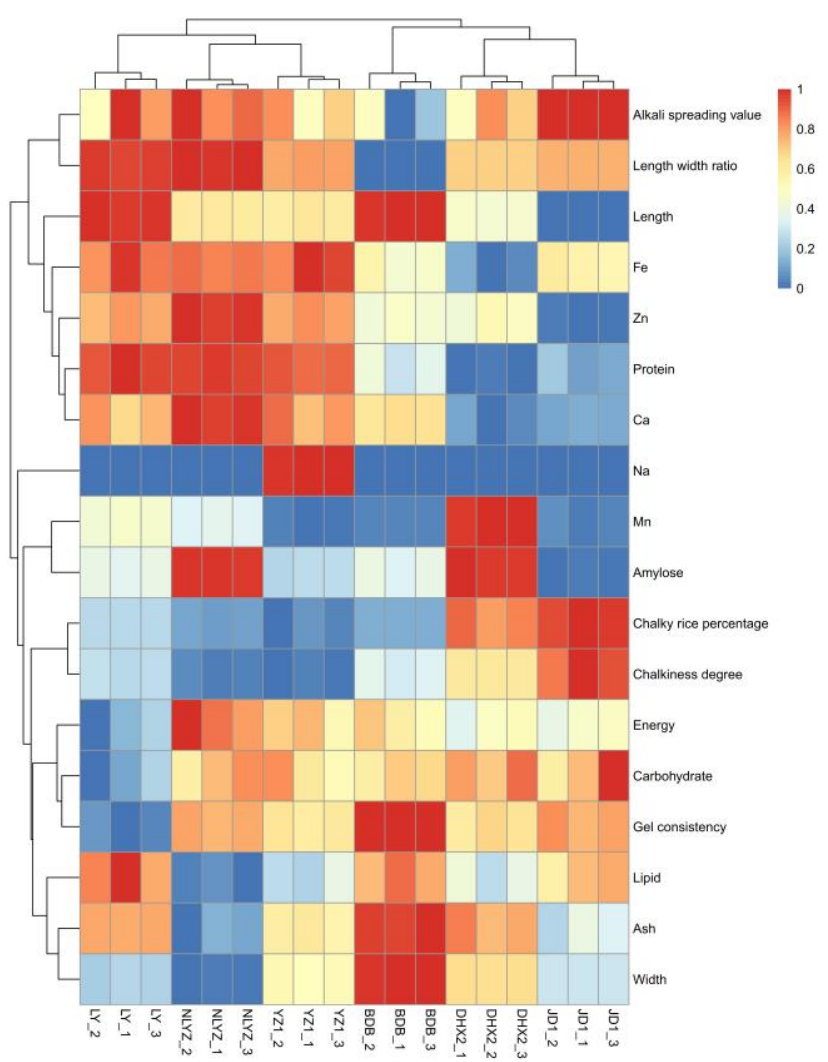

Fig. 2. Heatmap of cluster analysis of 18 rice samples from Xingan Meng

\subsection{Correlation}

The correlation relationship between nutritional composition, kernel morphology, and cooking quality were illustrated in Fig. 3. A positive and significant correlation was found between protein and $\mathrm{Ca}, \mathrm{Fe}, \mathrm{Zn}$. $\mathrm{Ca}$ was found to be positively and significantly correlated with $\mathrm{Zn}$ and $\mathrm{Fe}$ content. As for kernel morphology, the protein content was found to be negatively and significantly correlated with chalkiness degree and the chalky rice percentage. When it comes to cooking quality, gel consistency were weakly correlated with energy and carbohydrate. Alkali spreading value correlated with length width ratio positively. Similar results indicated that cooking and eating quality of rice had significant correlation with grain shapes characters, chalky characters, milling quality, nutritional quality and 
RVA profile characteristics ${ }^{[20]}$. Another report noted that the influence of rice size on their nutritional components $^{[21]}$.

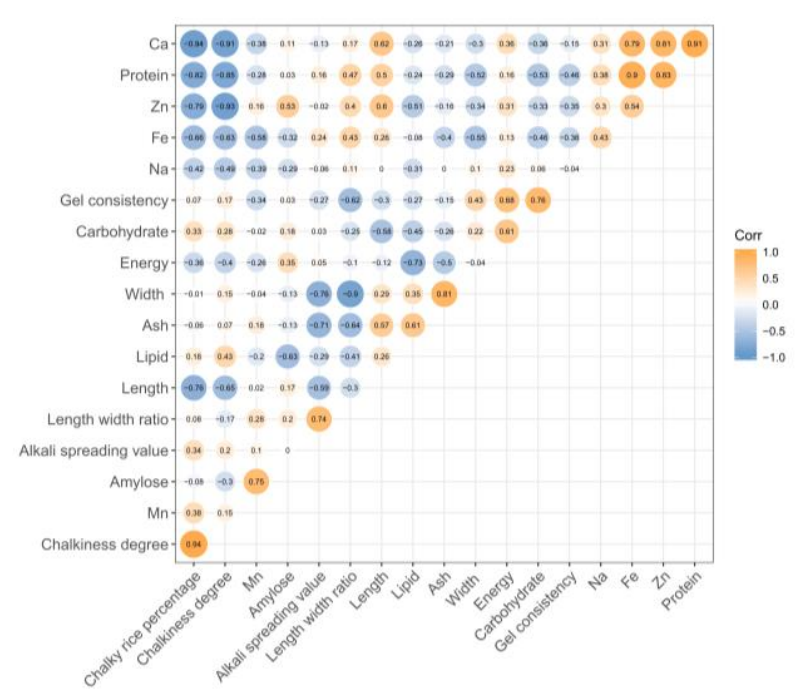

Fig. 3. Heat map representing Pearson's correlation coecients between nutritional composition, kernel morphology, and cooking quality.

\section{Conclusion}

The rice samples in this study showed considerable variability in levels of nutritional composition, kernel morphology and cooking quality. This variability can be exploited in the rice breeding programs. Principle component analysis extracted four components that explained $95.14 \%$ of the total variation. The 18 rice samples were grouped into four distinct clusters, based on nutritional, kernel morphology, and cooking quality. A positive and significant correlation was found between protein and $\mathrm{Ca}, \mathrm{Fe}, \mathrm{Zn}$. The findings of this study will help to demonstrate the quality of rice from Xingan Meng.

\section{Acknowledgements}

This study was supported by the research grant of "Nei Meng Gu Brand" Certification. We also wish to thank Zhailaiteqi Chuole Yinzhu Rice Co., Ltd. Dr. Yixing Tian is acknowledge for plotting the heatmap of cluster analysis and correlation analysis.

\section{References}

1. S. P. Batres-Marquez, H. H. Jensen, \& J. Upton. Journal of the American Dietetic Association, 109(10):1719-1727.(2009)

2. K. Clauss, H. Yan, \& C. Kuenzer. Remote Sensing, 8(5):434.(2016)

3. X. Deng, J. Huang, S. Rozelle, et al. Land Use Policy, 23(4):372-384.(2006)

4. M. Fan, J. Shen, L. Yuan, et al. Journal of Experimental Botany,63(1):13-24.(2012)
5. B. K. Yadav, \& V. K. Jindal. Journal of Food Engineering, 80(1):46-54.(2007)

6. G. K. Thind, \& D. S. Sogi. Food Chemistry,91(2):227-233.(2005)

7. N. M. Vaingankar, \& P. R. Kulkarni. Journal of the Science of Food \& Agriculture,48:381-384.(2010)

8. AOAC, 2005a, Gaithersburg, MD, USA.

9. AOAC, 2005b, Gaithersburg, MD, USA.

10. AOAC, 2005c, Gaithersburg, MD, USA.

11. AOAC, 2000, Gaithersburg, MD, USA.

12. M. Mariotti, L. Fongaro, \& F. Catenacci. Journal of Cereal Science,52(2):227-235.(2010)

13. B. Peng, K.-Y. Kong, T.-Y. Nassirou, et al. Journal of Agricultural Science,10(7):156-166.(2018)

14. H. Zhang, G. Zhou, D. L. Liu, et al. Science of the Total Environment, 666:126-138.(2019)

15. C. Maione, \& R. M. Barbosa. Critical reviews in food science and nutrition,59(12):1868-1879.(2019)

16. K. A. Sanni, I. Fawole, A. Ogunbayo, et al. Crop Science,52(2):494-504.(2012)

17. T. Longvah, \& V. S. S. Prasad. Food Chemistry,318:126385.(2020)

18. T. S. Madhulatha. IOSR-JEN,2:719-725.(2012)

19. A. Ali, H. A. Sadaqat, M. Kashif, et al. Pakistan journal of agricultural sciences, 55: 793-799.(2018)

20. C. Shuqiang. Acat Agriculturae Boreali-Occidentalis Sinica(24):60-67.(2015)

21. R. Jianhua, Z. Zhengmao, H. Binbo, et al. Science \& Technology of Food Industry, 27:54-56.(2006) 